\title{
Silencing of lncRNA PART1 inhibits proliferation, invasion and migration of breast cancer cells and promotes the efficacy of cisplatin in breast cancer cells
}

\author{
Li Zhang ${ }^{1}$, Jie Zhang ${ }^{2}$ and Chuandou $\mathrm{Ni}^{1}$ \\ ${ }^{1}$ Department of Surgery, The Affiliated Wenling Hospital of Wenzhou Medical University, Wenling, Zhejiang, China \\ ${ }^{2}$ Department of Pathology, The Affiliated Wenling Hospital of Wenzhou Medical University, Wenling, Zhejiang, China
}

\begin{abstract}
LncRNAs have proved to be related to the progression of multiple cancers. The present study aimed to investigate the effect of PART1 on the proliferation, invasion and migration of breast cancer cells and the efficacy of cisplatin in these cells. The expression of lncRNA PART1 in tissues and cells were detected by RT-qPCR analysis which was also used to verify the transfection effects. The cell proliferation, invasion and migration of breast cancer cells were respectively analyzed by CCK-8 assay, transwell assay and wound healing assay. The cell apoptosis was determined by flow cytometry analysis. The detection of CDK2, cyclinE1, P21, MMP3, MMP10, MMP13, Bcl2, Bax, cleaved caspase-3, caspase-3, MDP1, MRP1, GST- $\pi$ and ABCB1 expression was performed by Western blot analysis. The results revealed that PART1 was increased in breast cancer tissues and cells, silencing of PART1 significantly inhibited cell proliferation, invasion and migration by regulating the expression of relative proteins. In addition, silencing of PART1 obviously improved the sensitivity of breast cancer cells to cisplatin, promoted cell apoptosis, and decreased the expression of breast cancer resistance proteins. In conclusion, silencing of PART1 inhibited proliferation, invasion and migration of breast cancer cells and promoted the efficacy of cisplatin in these cells. Therefore, PART1 may be considered as a novel therapeutic target in breast cancer.
\end{abstract}

Key words: LncRNA PART1 — Proliferation - Invasion and migration - Breast cancer cells Cisplatin

\section{Introduction}

Breast cancer is a frequently-occurring female malignant tumor, which seriously endangers life and health of women (Desantis et al. 2015; Siegel et al. 2015; Shi et al. 2017). It is listed as one of the ten common cancers in the world (Aebi et al. 2009). Despite significant progress in surgical resection and chemoradiotherapy (Gradishar et al. 2017), chemotherapeutic resistance of tumor cells is still a difficult clinical problem to treat breast cancer. Once drug resistance occurs in patients, there will be no effective clinical interventions, with poor prognosis (Masoud and Pagés 2017). At present, breast cancer is still the main cause of female deaths in the

Correspondence to: Li Zhang, Department of Surgery, The Affiliated Wenling Hospital of Wenzhou Medical University, Chuanan Nan Road 333\#, Chengxi subdistrict, Wenling 317500, Zhejiang, China E-mail: lzhang9698@163.com world (Donepudi et al. 2014; Chan et al. 2017; Dreyer et al. 2017). Therefore, it is necessary for us to further discover new and effective treatment methods for this disease.

Encouragingly, studies have demonstrated the regulation effects of circular RNA (circRNA), long non-coding RNA (lncRNA) and microRNA (miRNA) in the development and progression of various cancers (Anastasiadou et al. 2017). Longer than 200 nucleotides, lncRNA is a kind of RNA with no protein-coding ability ( $\mathrm{Li}$ et al. 2016). It is often associated with invasion and metastasis of tumor and cell growth, and its abnormal expression and function changes can significantly affect the occurrence and development of various malignant tumors (Bhan et al. 2017; Ming-Yu et al. 2017). Moreover, lncRNA may trade as potential biomarkers of diagnosis, prognosis and therapeutic targets (Eduardo et al. 2012). The expression of IncRNA PART1 was increased in the prostate cancer cells induced by $5 a$-dihydrotestosterone (DHT) and silencing of PART1 suppressed proliferation 
and accelerated apoptosis of prostate cancer cells (Sun et al. 2018). The expression of PART1 was upregulated in gefitinibresistant esophageal squamous cell carcinoma (ESCC) cells and PART1 interference accelerated cell death while PART1 overexpression promoted gefitinib resistance (Kang et al. 2018). In bladder cancer, knockdown of PART1 restrained cell proliferation and invasion, and accelerated cell apoptosis (Hu et al. 2019). Cruickshank et al. (2019) demonstrated the role of PART1 in cell proliferation and stem cell maintenance in triple-negative breast cancer. Therefore, we speculate that PART1 may regulate the proliferation, invasion and migration of breast cancer cells and the cytotoxic effects of cisplatin (DDP) on drug-resistant cells.

In the present study, the PART1 expression has been verified in breast cancer tissues and cells. The effects of PART1 on the proliferation, invasion and migration of breast cancer cells and the efficacy of cisplatin in breast cancer cells were investigated, and the potential mechanism of PART1 was further explored.

\section{Materials and Methods}

\section{Clinical samples}

Thirty patients with breast cancer characteristic of nipple changes, pain in the breast, breast skin changes and lumps in the breast were enrolled from the First People's Hospital of Wenling. The breast cancer tissues and paired adjacent normal tissues were collected from patients with breast cancer at the First People's Hospital of Wenling. The breast cancer tissue from each enrolled patient was verified by pathological observation. And, every patient had signed the consent form. All the tissues were snap-frozen in liquid nitrogen and then stored at $-80^{\circ} \mathrm{C}$ for the subsequent experiments.

\section{Cell culture}

MCF-10A, MCF-7, T47D, MDA-MB-435 and BT-549 cells were bought from American Type Culture Collection (Rockville, MD, USA). The cell lines were cultured in DMEM medium (Gibco; Thermo Fisher Scientifc, Inc., Waltham, MA, USA) containing $10 \%$ fetal bovine serum (FBS) under the condition of $37^{\circ} \mathrm{C}, 5 \% \mathrm{CO}_{2}$ and $95 \%$ humidity.

\section{Cell transfection and cisplatin treatment}

Breast cancer cells were inoculated in 24-well plates and grew into confluence of 70-80\%. ShRNA-NC, ShRNA-PART1-1, ShRNA-PART1-2 were transfected into breast cancer cells using Lipofectamine 2000 reagent (Invitrogen; Thermo Fisher Scientific, Inc., Waltham, MA, USA), which were correspondingly ShRNA-NS group, ShRNA-PART1-1 group and
ShRNA-PART1-2 group. In the Control group, breast cancer cells were not treated by any medicine. After cell transfection for $48 \mathrm{~h}$, breast cancer cells were treated with cisplatin at the concentrations of $0.0001,0.01,0.1,1,10$ and $100 \mu \mathrm{M}$.

\section{Generation of cisplatin -resistant cell line}

The MCF-7 cells and T47D cells were inoculated in 24-well plates and grew into confluence of $70-80 \%$. Then, MCF-7 cells and T47D cells were induced by $10 \mu \mathrm{M}$ cisplatin for 2 days. Two days later, MCF-7 cells and T47D cells were washed and transferred to regular medium without cisplatin for another 2 days. The above procedure was repeated for 4-6 weeks. Cisplatin-resistant MCF-7 cells and T47D cells were named as MCF7/DDP cells and T47D/DDP cells.

\section{RT-qPCR analysis}

Cells of each group at logarithmic growth phase were obtained with appropriate amount. Total RNA was extracted with Trizol lysate (Invitrogen; Thermo Fisher Scientific, Inc.). cDNA was transcribed by reverse transcription kit (Takara Biotechnology Co., Ltd., Beijing, China) and amplified by RT-PCR with SYBR Green I dye (Invitrogen; Thermo Fisher Scientific, Inc.). The reaction condition was as follows: $95^{\circ} \mathrm{C}$ pre-denaturation for $30 \mathrm{~s}, 95^{\circ} \mathrm{C}$ denaturation for $5 \mathrm{~s}, 60^{\circ} \mathrm{C}$ annealing for $30 \mathrm{~s}, 30$ cycles of amplification, and $72^{\circ} \mathrm{C}$ terminal extension for $3 \mathrm{~min}$. U6 was considered as an internal reference and the expression of PART1 was detected by the $2^{-\Delta \Delta C t}$ method.

\section{CCK-8 assay}

After cell transfection for $48 \mathrm{~h}$, breast cancer cells in 96well plates were treated with cisplatin at the concentrations of $0.0001,0.01,0.1,1,10$ and $100 \mu \mathrm{M}$. After the following cell culture in the incubator for $72 \mathrm{~h}, 10 \mu \mathrm{l} \mathrm{CCK}-8$ solution was added to each well, which was incubated afterwards in the incubator for $2 \mathrm{~h}$. The absorbance value at $\mathrm{A}_{450 \mathrm{~nm}}$ was determined by a SynergyTM 2 Multi-function Microplate Reader (BioTek Instruments, Inc., Winooski, VT, USA). After cell transfection for $48 \mathrm{~h}, \mathrm{MCF}-7 / \mathrm{DDP}$ cells and T47D/ DDP cells were treated with $10 \mu \mathrm{M}$ cisplatin. The following experimental process was the same as the above experiment.

\section{Western blot analysis}

The proteins in the breast cancer cells were extracted according to the instructions of the cell protein extraction kit (Biocolors Biotechnology Co., Shanghai, China). According to the instructions of the Western blot kit, $80 \mu \mathrm{g}$ of protein was added to each well for cell electrocoagulation by $12 \%$ SDS-PAGE, and then the protein was transferred to PVDF 
membrane (Merck Millipore, Billerica, MA, USA). PVDF membrane was sealed with $5 \%$ skim milk powder and incubated against CDK2, cyclinE1, P21, MMP3, MMP10, MMP13, Bcl2, Bax, cleaved caspase-3, caspase-3, MDP1, MRP1, GST- $\pi$, ABCB1 and GAPDH on the shaking bed overnight at $4^{\circ} \mathrm{C}$. Then, PVDF membrane was incubated with the secondary antibody for $1 \mathrm{~h}$, washed with TBST for $30 \mathrm{~min}$, and developed by electrochemiluminescence (ECL). GAPDH was used as internal reference, and ImageJ software was used to analyze the optical density of relative bands.

\section{Wound healing assay}

Cells of each group were taken and inoculated into 6-well plates with the density of $1 \times 10^{6} / \mathrm{ml}$. When the cells were completely covered, a vertical line was drawn with a $10 \mu \mathrm{l}$ tip on the well. Cells were washed with phosphate buffer solution (PBS) for 3 times and photographed under an inverted microscope. The images were labeled as $0 \mathrm{~h}$. Then, $10 \%$ fetal bovine serum was added and cells were continuously cultured for $24 \mathrm{~h}$. The images were taken under an inverted microscope, which were labeled as $24 \mathrm{~h}$. And, the $0 \mathrm{~h}$ images were taken as a reference. The relative cell migration was analyzed by ImageJ software.

\section{Transwell assay}

Matrigel gel was mixed with serum free medium at a ratio of $8: 1$. In the 24 -well transwell plate, $250 \mu$ mixture was added to upper chamber, followed by adding $100 \mu \mathrm{l}$ hydrated basement membrane with serum free medium. The cell density was adjusted to $2.5 \times 10^{5} / \mathrm{ml}$ and $200 \mu \mathrm{l}$ cell suspension was added to upper chamber. $600 \mu \mathrm{l}$ DMEM medium containing $20 \%$ FBS was added to lower chamber. The 24-well transwell plate was cultured for $24 \mathrm{~h}$. Transwell indoor liquid was discarded, and the inner surface cells at the bottom of upper chamber were lightly wiped with cotton swab. Then, chambers were intruded into 95\% ethanol and fixed for $5 \mathrm{~min}$, followed by staining with $200 \mu \mathrm{l}$ $4 \mathrm{~g} / \mathrm{l}$ crystal violet for $10 \mathrm{~min}$. Each sample was randomly selected from 6 fields under an inverted microscope, photographed and counted.

\section{Flow cytometry analysis}

After transfection and cisplatin $(10 \mathrm{nM})$ treatment for $72 \mathrm{~h}$, cells of each group were collected, centrifuged at 3100 rate per minute for $5 \mathrm{~min}$ and the supernatant was discarded. The experimental groups were: Control group, Control+cisplatine (cis) group, ShRNA+cis group and ShRNA-PART1-1+cis group. Cells were washed by PBS. Then, cells were resuspended in $500 \mu \mathrm{l}$ binding buffer and stained with $5 \mu \mathrm{l} \mathrm{An-}$ nexin V-FITC and $10 \mu$ Polyimide (PI) for $15 \mathrm{~min}$ in the dark at room temperature. The proportion of apoptotic cells was detected by flow cytometry.

\section{Statistical analysis}

SPSS 22.0 was used to analyze the data which are presented as mean \pm standard deviation (SD). Comparison of the mean values of multiple groups was conducted by single factor analysis of variance (ANOVA), with least significant difference (LSD) method used for pairwise comparison. Comparison of the mean values of two groups was conducted by T-test. A $p$ value $<0.05$ was statistically significant.

\section{Ethics approval and consent to participate}

The study was approved by the Ethics committee of the First People's Hospital of Wenling. The participants provided written informed consent to participate in the study.

\section{Results}

\section{PART1 was increased in breast cancer tissues and cells}

The expression of PART1 in breast cancer tissues and cells was detected by RT-qPCR analysis. The expression of PART1 was increased in breast cancer tissues compared with adjacent tissues (Fig. 1A) and was increased in MCF-7, T47D,
A

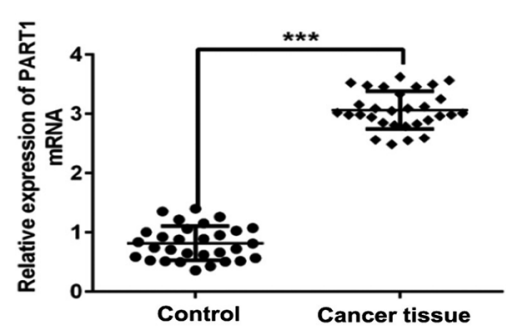

B

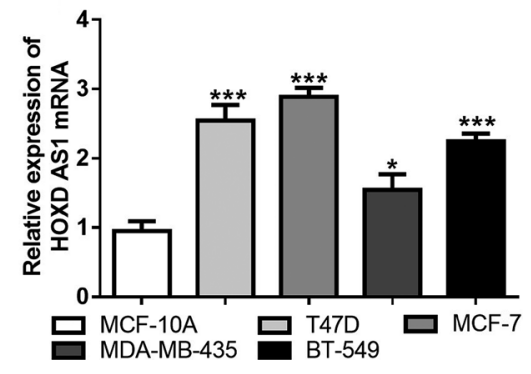

Figure 1. A. PART1 was increased in breast cancer tissues compared with the paired adjacent normal tissues (Control). B. PART1 was increased in breast cancer cells (T47D, MCF-7, MDA-MB-435, BT-549) compared with MCF10A cells. ${ }^{*} p<0.05,{ }^{* * *} p<0.001$ vs. MCF-10A group. 


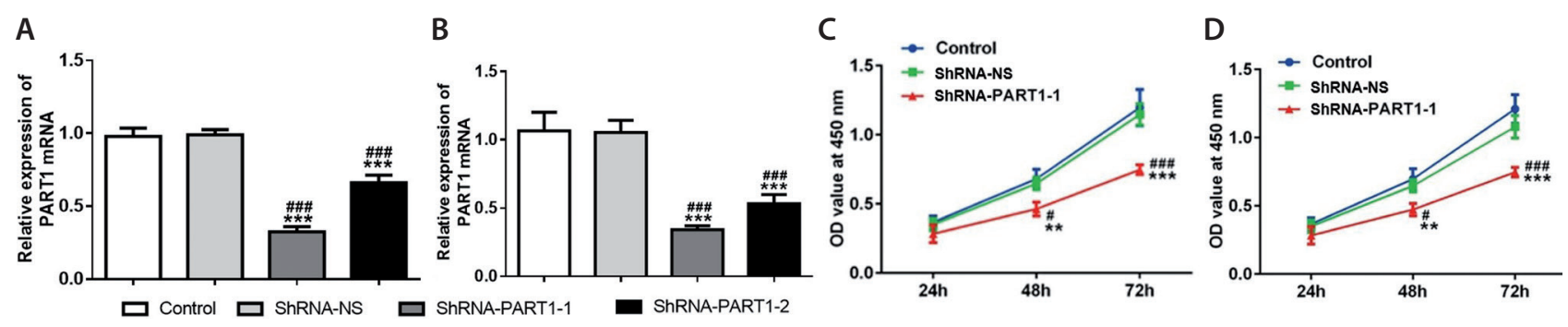

Figure 2. Silencing of PART1 inhibited proliferation of breast cancer cells. The PART1 expression was decreased in MCF-7 cells (A) and in T47D cells (B) transfected with ShRNA-PART1. The proliferation of MCF-7 cells $($ C) and T47D cells (D) were decreased after transfection of ShRNA-PART1. ${ }^{* *} p<0.01,{ }^{* * *} p<0.001 v$ s. Control group; ${ }^{\#} p<0.05,{ }^{\# \# \#} p<0.001 v$ s. ShRNA group.

MDA-MB-435 and BT-549 cells compared with MCF-10A cells (Fig. 1B). The expression of PART1 in MCF-7 and T47D cells was higher than the expression in MDA-MB-435 and BT-549 cells. Therefore, MCF-7 and T47D cells were selected for the subsequent experiments.

\section{Silencing of PART1 inhibited proliferation of breast cancer cells}

The transfection effects of ShRNA-PART1 on the MCF-7 and T47D cells were confirmed by RT-qPCR analysis. PART1 ex- pression in MCF-7 and T47D cells was decreased when cells were transfected with ShRNA-PART1 (Fig. 2A, B). PART1 expression in ShRNA-PART1-1 group was less than that in ShRNA-PART1-2 group, so ShRNA-PART1-1 was selected for the subsequent experiments. The proliferation of MCF7 and T47D cells was suppressed compared with those in Control group and ShRNA group (Fig. 2C, D). In addition, the expression of CDK2 and cyclinE1 in MCF-7 and T47D cells transfected with ShRNA-PART1-1 was decreased while P21 expression was increased (Fig. 3). Collectively, the results

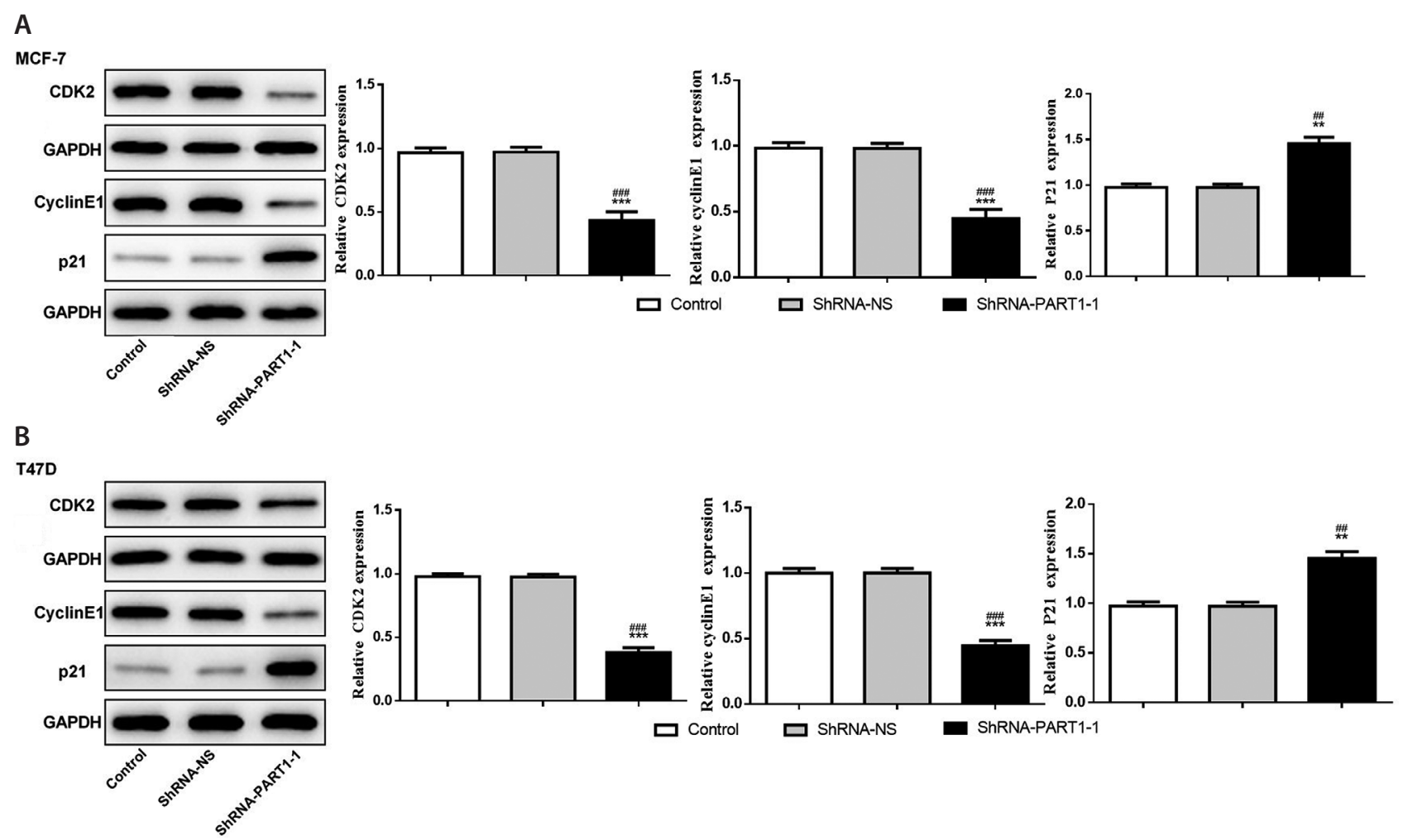

Figure 3. Silencing of PART1 changed the proliferation related proteins in MCF-7 cells (A) and T47D cells (B). The expression of proliferation-related proteins were detected by Western blot analysis. ${ }^{* *} p<0.01,{ }^{* *} p<0.001 v$ s. Control group; ${ }^{\# \#} p<0.01,{ }^{\# \#} p<$ $0.001 v s$. ShRNA-NS group. 
indicated that silencing of PART1 inhibited proliferation of breast cancer cells.

\section{Silencing of PART1 inhibited invasion and migration of breast cancer cells}

Transwell assay and wound healing assay were used to analyze the invasion and migration of breast cancer cells. The migration and invasion rate of MCF-7 were obviously decreased in ShRNA-PART1-1 group (Fig. 4A, B). The protein expression of MMP3, MMP10 and MMP13 in MCF-7 cells, which was related to invasion and migration, was all decreased in ShRNA-PART1-1 group (Fig. 4C). The migration rate and invasion rate of T47D cells (Fig. 5A, B) and the protein expression of MMP3, MMP10 and MMP13 in T47D cells was all decreased (Fig. 5C). Therefore, the findings showed that silencing of PART1 inhibited invasion and migration of breast cancer cells.

Silencing of PART1 promoted the efficacy of cisplatin in breast cancer cells

CCK-8 assay detected the cell viability. As shown in Figure 6, the IC50 of MCF-7 and T47D cells in Control group and
A
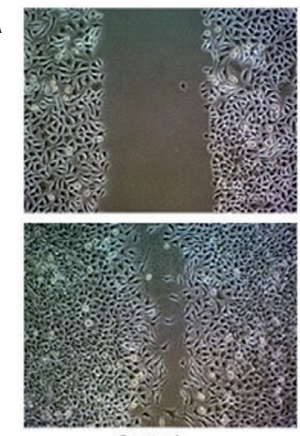

Control

B

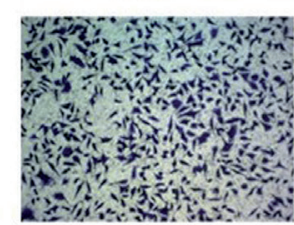

Control
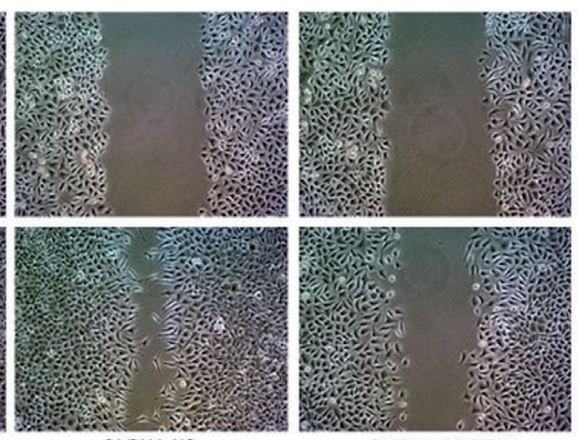

SHRNA-PART1-1
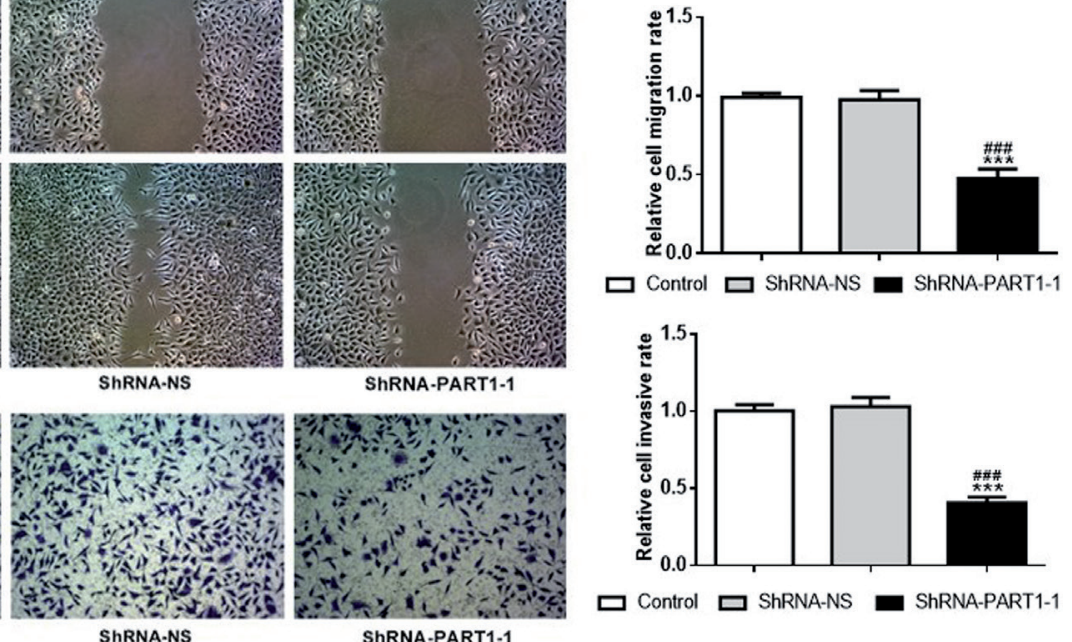

ロ Control घShRNA-NS $\square$ ShRNA-PART1-1

C
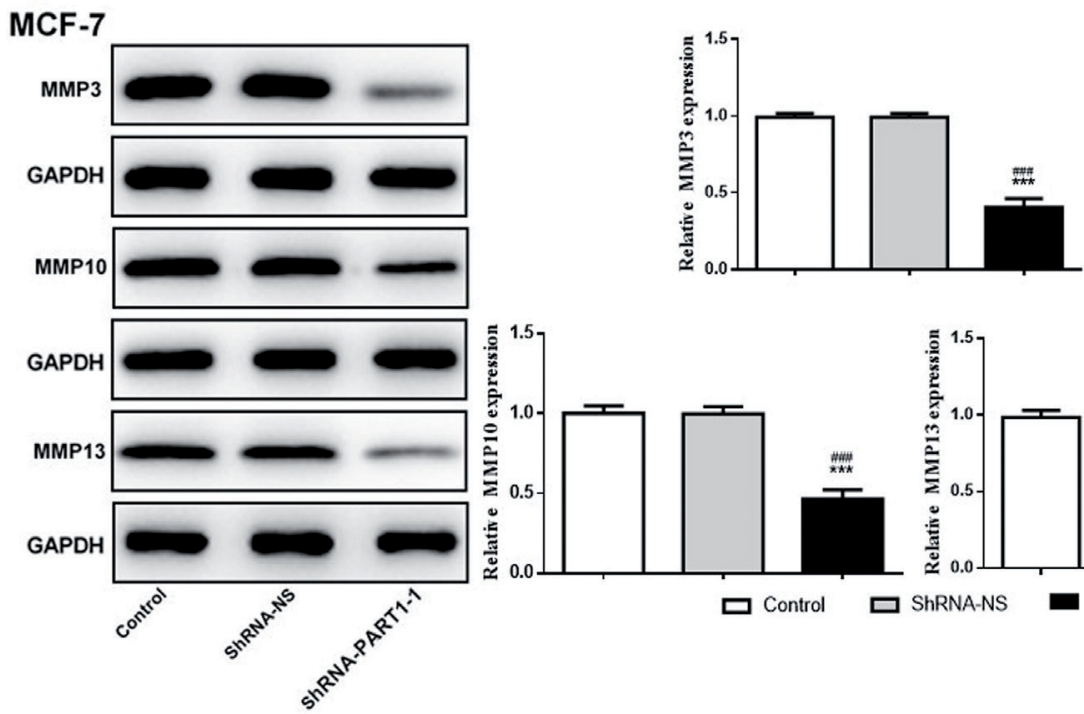

$\square$ Control

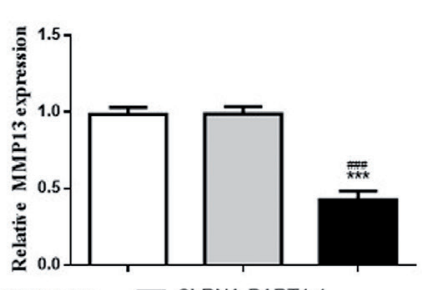

ShRNA-NS

- ShRNA-PART1-1

Figure 4. Silencing of PART1 inhibited invasion and migration of MCF-7 cells. The migration (A) and invasion (B) of MCF-7 cells was decreased after transfection of ShRNA-PART1. C. The migration of MCF-7 cells was decreased after transfection of ShRNA-PART1. ${ }^{* * *} p<0.001$ vs. Control group; ${ }^{\# \# \#} p<0.001$ vs. ShRNA-NS group. 
ShRNA-NC group was about $0.8 \mu \mathrm{M}$ and the IC50 of MCF-7 and T47D cells in ShRNA-PART1-1 group was $0.02 \mu \mathrm{M}$. The concentration of cisplatin at $0.02 \mu \mathrm{M}$ was selected for the subsequent study. The above results demonstrated that silencing of PART1 increased the sensitivity of breast cancer cells to cisplatin.
Silencing of PART1 promoted apoptosis of breast cancer cells treated by cisplatin

The cell apoptosis was detected by flow cytometry analysis. The apoptosis of MCF-7 and T47D cells was increased when MCF-7 and T47D cells were treated with $0.02 \mu \mathrm{M}$

A
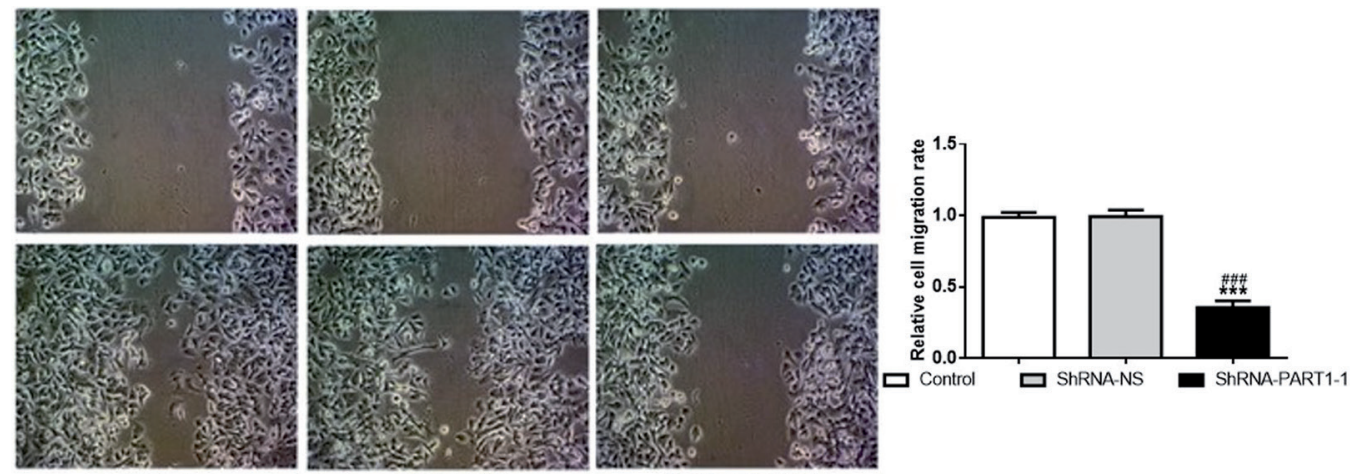

B

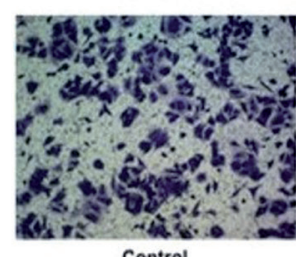

ShRNA.NS

ShRNA.PART1-1
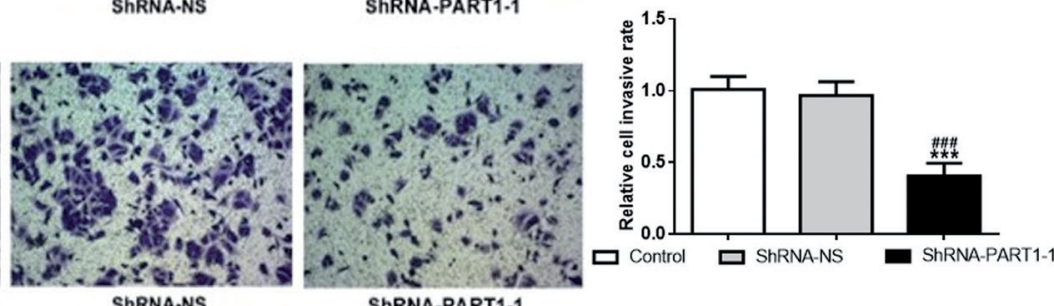

C

T47D
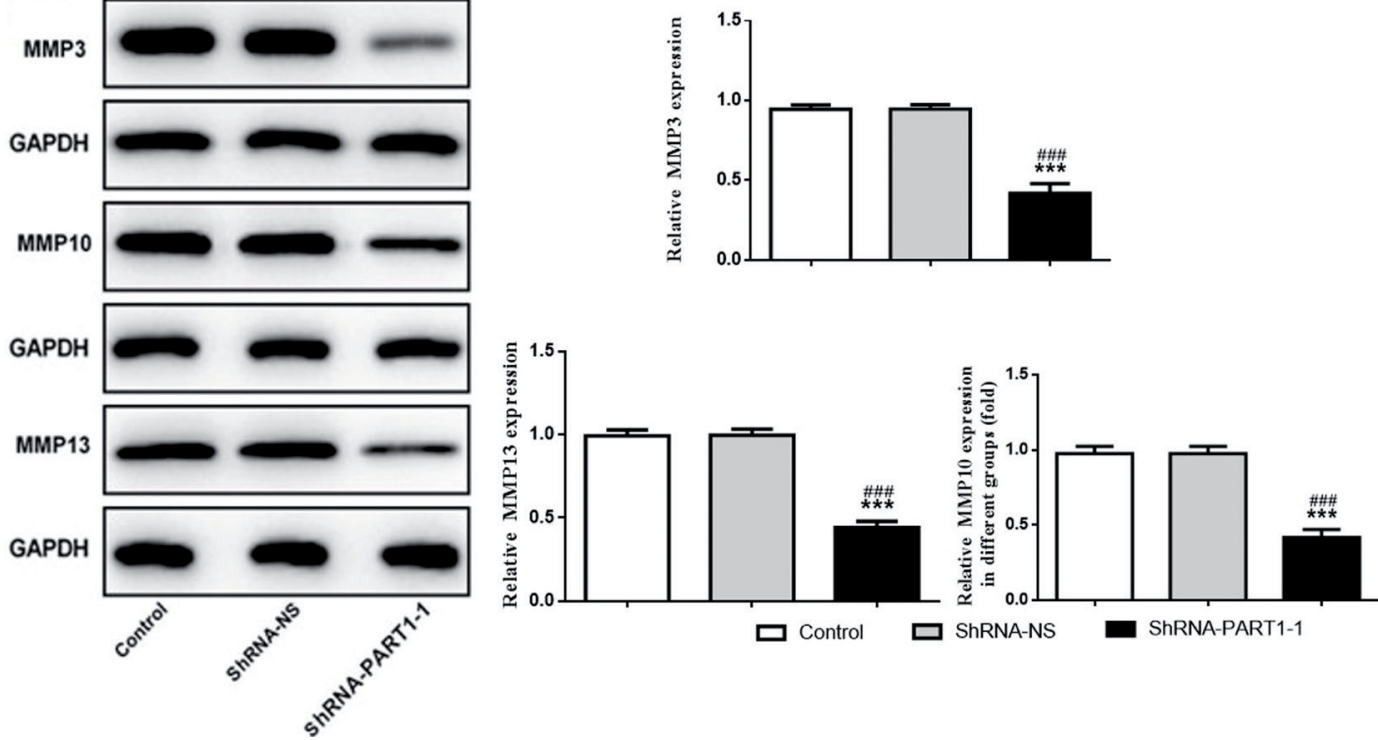

Figure 5. Silencing of PART1 inhibited invasion and migration of T47D cells. A. The migration of T47D cells was decreased after transfection of ShRNA-PART1. B. The related proteins of invasion and migration were decreased in T47D cells transfected with shRNA-PART1. C. The related proteins of invasion and migration were decreased in T47D cells transfected with ShRNA-PART1. ${ }^{* * *} p<0.001 v s$. Control group; ${ }^{\# \#} p<0.001$ vs. ShRNA-NS group. 
cisplatin. When MCF-7 and T47D cells were transfected with ShRNA-PART1-1 previously, the apoptosis of MCF-7 and T47D cells treated with $0.02 \mu \mathrm{M}$ cisplatin was improved (Fig. 7). In addition, the expression of $\mathrm{Bcl} 2$ was decreased and the expression of Bax and cleaved caspase- 3 was increased in MCF-7 and T47D cells in ShRNA-PART1-1+cis group compared with Control+cis group and ShRNA+cis group (Fig. 8). Therefore, silencing of PART1 promoted apoptosis of breast cancer cells treated with cisplatin.

\section{Silencing of PART1 reversed the resistance of MCF-7/DDP} cells and T47D/DDP cells to DDP

The proliferation of MCF-7/DDP cells and T47D/DDP cells transfected with ShRNA-PART1-1 was decreased after the treatment of cisplatin (Fig. 9). The expression of resistanceassociated proteins including MDP1, MRP1, GST- $\pi$ and $\mathrm{ABCB} 1$ was decreased in MCF-7/DDP cells and T47D/DDP cells transfected with ShRNA-PART1-1 (Fig. 10). Therefore, silencing of PART1 reversed the resistance of MCF-7/DDP cells and T47D/DDP cells to cisplatin through down-regulating the expression of resistance proteins.

\section{Discussion}

Here, the effects of PART1 on the proliferation, invasion and migration of breast cancer cells and the efficacy of cisplatin in breast cancer cells have been explored in this study. We found that PART1 expression was increased in breast cancer tissues and cells, and silencing of PART1 inhibited proliferation, invasion and migration of breast cancer cells, at the same time promoted the efficacy of cisplatin in these cells.

More than $90 \%$ of genome is actively transcribed, which crucially regulates the cell state (Birney et al. 2007; Gibb et al. 2011). In the development of breast cancer, abnormal expression of multiple genes contributed to the deterioration of breast cancer. Among the abnormally expressed genes such as IncRNA CDC6, FOXD3-AS1, TRPM2-AS and POU3F3, the extremely important lncRNAs often show suppression and promotion effects on cancer cells (Guan et al. 2019; Kong et al. 2019; Sun et al. 2019a; Yang et al. 2019).

Nowadays, great amounts of existing studies demonstrated that lncRNAs were involved in breast cancer and abnormal expression of lncRNAs could deteriorate the cancers (Fu et al. 2019; Sun et al. 2019b; Wang et al. 2019). In this study, we found that PART1 expression was obviously increased in breast cancer tissues and cells. Furthermore, silencing of PART1 suppressed the proliferation of breast cancer cells. Meanwhile, proliferation-related proteins were detected, and silencing of PART1 distinctly inhibited the expression of CDK2 and cyclinE1 as well as promoted the P21 expression. CDK2 can bind to cyclinE and cyclinA to
A

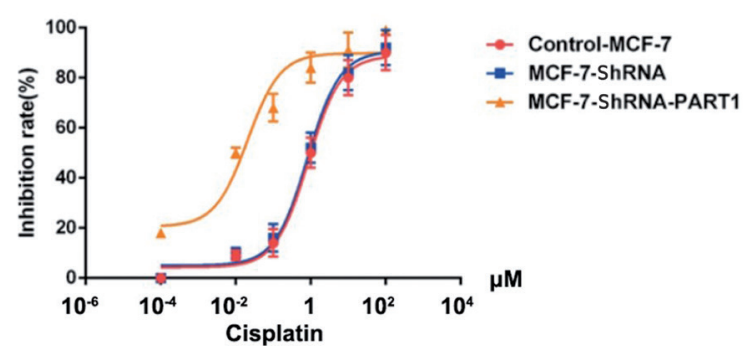

B

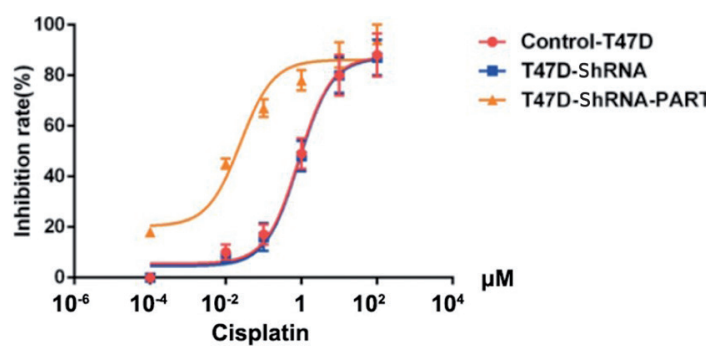

Figure 6. Silencing of PART1 promoted the efficacy of cisplatin in breast cancer cells. The IC50 value of MCF-7 cells (A) and T47D cells (B) for cisplatin was decreased after transfection of ShRNAPART1.

promote cell division and cell cycle progression. If CDK2 is always in a highly active state, it will be able to disrupt the cell cycle process, leading to malignant cell proliferation and tumor formation (Xie 2009). P21 is a broad-spectrum cycle-dependent kinase inhibitor and negative regulator of the cell cycle, which can inhibit cell proliferation and repair damaged or miscopied DNA by blocking G1/S transformation of the cell cycle. Therefore, P21 is generally considered to be a tumor suppressor gene (Nie et al. 2015; Ong et al. 2015; Shi et al. 2015). Moreover, silencing of PART1 also inhibited the invasion and migration of breast cancer cells and down-regulated the expression of MMP3, MMP10 and MMP13. Wu et al. (2019) found that lncRNA HCP5 was obviously decreased in MDA-MB-231/DDP cells compared with MDA-MB-231 cells, and HCP5 interference decreased the efficacy of cisplatin in MDA-MB-231 cells. In this study, silencing of PART1 promoted the efficacy of cisplatin in breast cancer cells by increasing their apoptosis. Caspase- 3 activation includes overexpression of Bax and simultaneous downregulation of Bcl-2 expression, which cause cell apoptosis (Hatok and Racay 2016; Ichim and Tait 2016). In addition, silencing of PART1 decreased the expression of drug resistance-associated proteins in the cisplatin -resistant breast cancer cells. ABCB1 is an important member of the $\mathrm{ABC}$ family that enables many chemotherapy drugs to pump out cells to induce multidrug resistance and other 


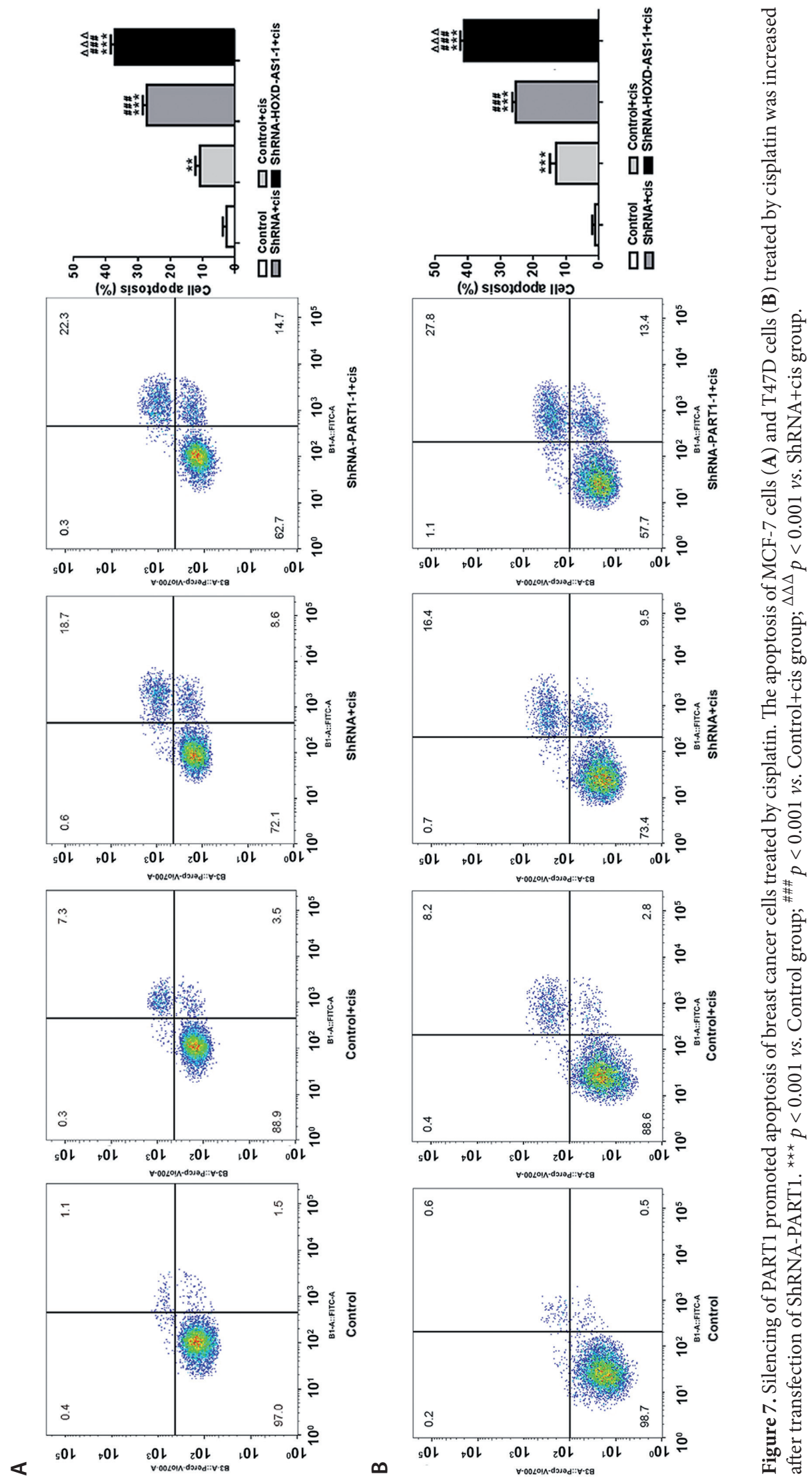


A
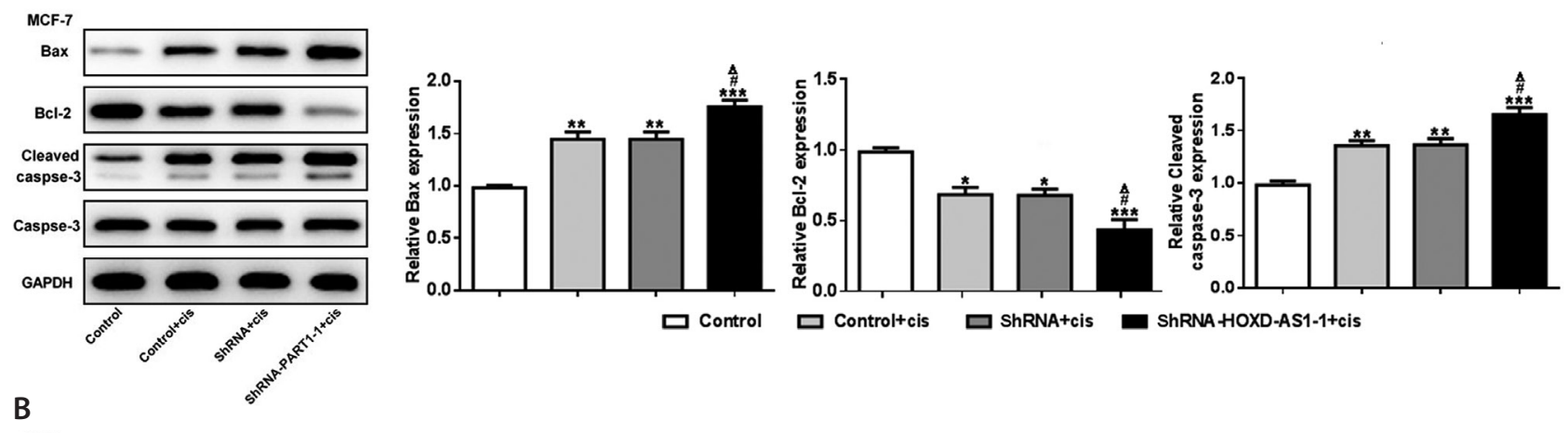

B
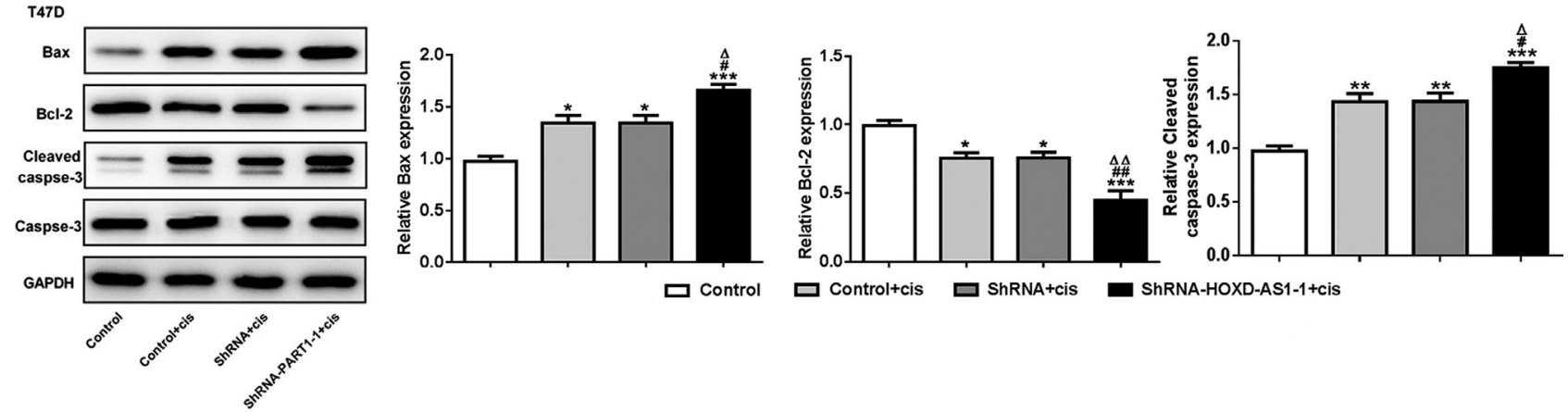

Figure 8. Silencing of PART1 changed the expression of apoptosis related proteins in breast cancer cells treated by cisplatin. The expression of apoptosis-related proteins MCF-7 (A) and T47D cells (B) cells treated by cisplatin was detected by Western blot analysis. ${ }^{\star} p<$ $0.05,{ }^{* *} p<0.01,{ }^{* * *} p<0.001 v$ s. Control group; ${ }^{\#} p<0.05,{ }^{\# \#} p<0.01 v s$. Control+cis group; ${ }^{\Delta} p<0.05,{ }^{\Delta \Delta} p<0.05 v s$. ShRNA+cis group.

members, including ABCC1 (multidrug resistance related protein, $\mathrm{MRP}$ ) and ABCG2 (breast cancer drug resistance protein, BCRP) (Mao 2005; Fojo and Coley 2007). GST- $\pi$ is involved in cell resistance to cisplatin, adriamycin and mitomycin C. Fan Zhang et al. (2001) found that preoperative untreated ovarian cancer had an intrinsic resistance mechanism mediated by GST- $\pi$ to some extent, and GST- $\pi$ expression could better predict chemotherapy response. Here, the expression of MDP1, MRP1, GST- $\pi$ and ABCB1 in MCF7/DDP cells and T47D/DDP cells was obviously decreased when MCF7/DDP cells and T47D/DDP cells transfected with ShRNA-PART1-1.

In conclusion, our present study showed that PART1 expression was increased in breast cancer tissues and cells. Silencing of PART1 inhibited proliferation, invasion and migration of breast cancer cells, and promoted the efficacy of cisplatin in breast cancer cells by increasing their apoptosis. Moreover, silencing of PART1 decreased the expression of drug resistance-associated proteins in the cisplatin-resistant breast cancer cells. PART1 provided for us with a new sight to treat the breast cancer and cisplatin-resistant breast cancer. However, the study is still limited because the nature of our research is in vitro, which is not persuasive compared with in vivo experiment. In the future, we will conduct in vivo experiments to enhance the credibility of experimental results.

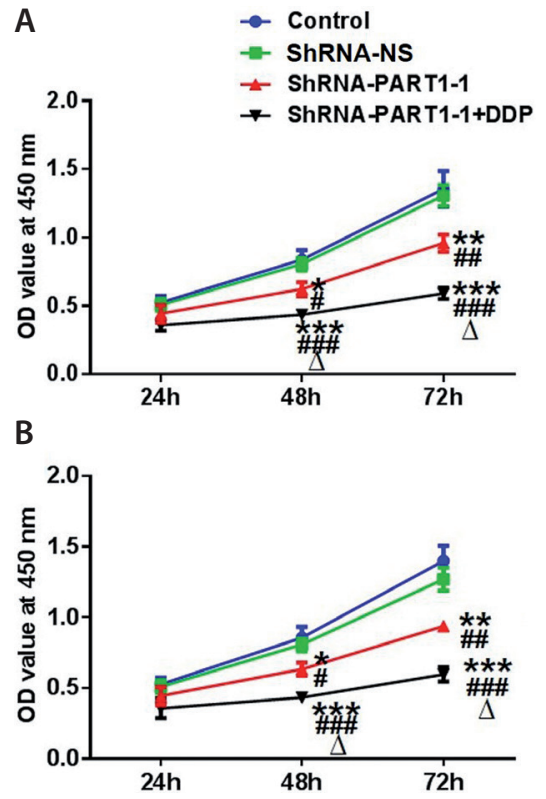

Figure 9. Silencing of PART1 inhibited proliferation of drug resistant human breast cancer cells. The proliferation of MCF-7/DDP cells (A) and T47D/DDP cells (B) in cisplatin was decreased after transfection of ShRNA-PART1. ${ }^{*} p<0.05,{ }^{* *} p<0.01,{ }^{* * *} p<0.001$ vs. Control group; ${ }^{\#} p<0.05,{ }^{\# \#} p<0.01,{ }^{\# \# \#} p<0.001 v s$. ShRNA-NS group; ${ }^{\Delta} p<0.05 v s$. ShRNA-PART1 group. 


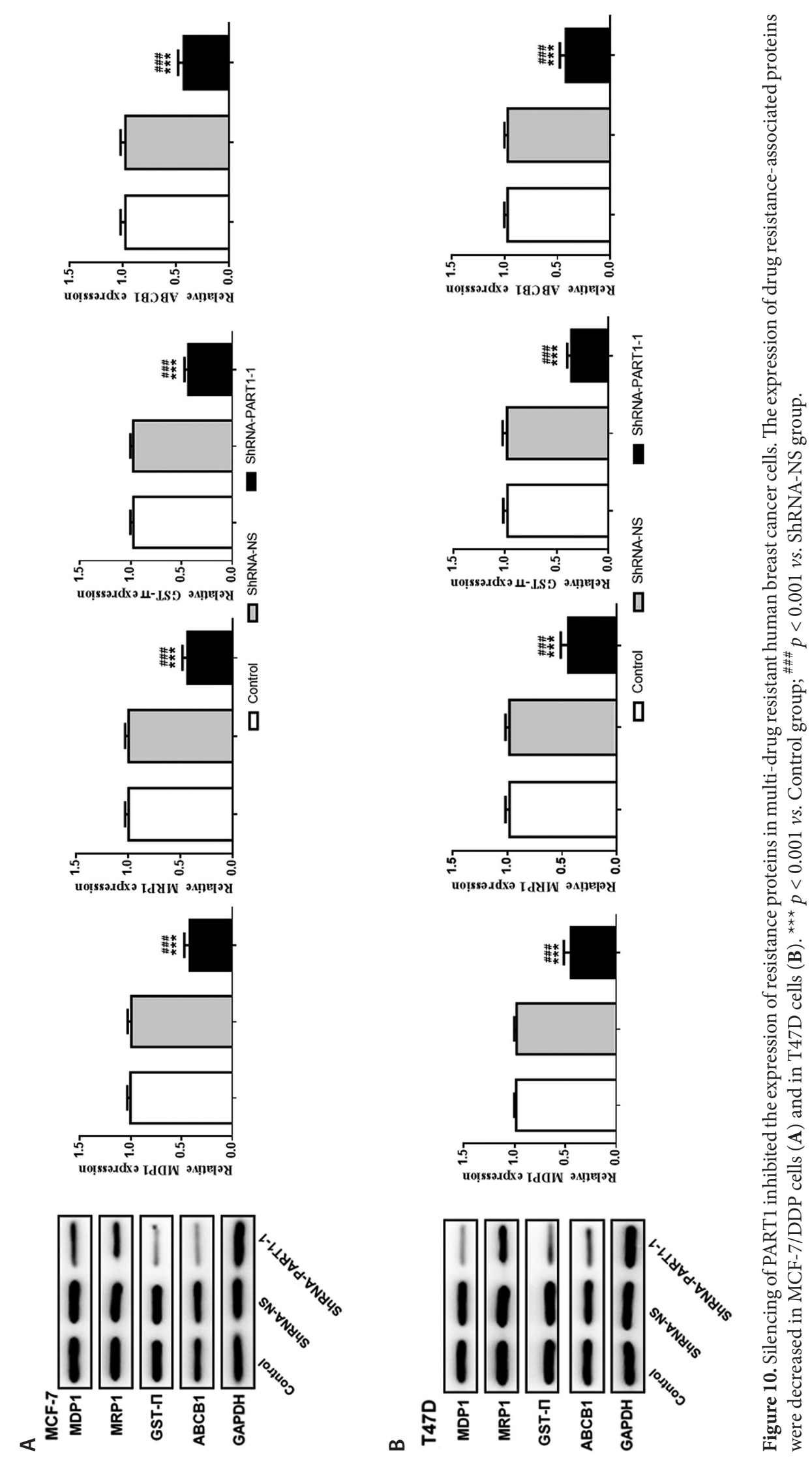


Acknowledgments. Thanks for the help of Yangli Zhu, director of Pathology Department in the Affiliated Wenling Hospital of Wenzhou Medical University.

Conflicts of interest. The authors declare they have no competing interests.

\section{References}

Aebi S, Davidson T, Gruber G, Castiglione M, Group EGW (2009): Primary breast cancer: ESMO clinical practice guidelines for diagnosis, treatment and follow-up. Ann. Oncol. 21, vi12-24 https://doi.org/10.1093/annonc/mdr371

Anastasiadou E, Slack FJ, Jacob LS (2017): Non-coding RNA networks in cancer. Nat. Rev. Cancer 18, 5-18 https://doi.org/10.1038/nrc.2017.99

Bhan A, Soleimani M, Mandal SS (2017): Long noncoding RNA and cancer: A new paradigm. Cancer Res. 77, 3965-3981 https://doi.org/10.1158/0008-5472.CAN-16-2634

Birney E, Stamatoyannopoulos JA, Dutta A, Guigó R, Gingeras TR, Margulies EH, Weng Z, Snyder M, Dermitzakis ET, Thurman RE, et al. (2007): Identification and analysis of functional elements in $1 \%$ of the human genome by the ENCODE pilot project. Nature 447, 799-816 https://doi.org/10.1038/nature05874

Chan CWH, Law BMH, So WKW, Chow KM, Waye MMY (2017): Novel strategies on personalized medicine for breast cancer treatment: an update. Int. J. Mol. Sci. 18, 2423-2441 https://doi.org/10.3390/ijms18112423

Cruickshank BM, Vidovic D, Dahn ML, Sultan M, Marcato P (2019): Long non-coding RNA PART1 contributes to cell proliferation and stem cell maintenance in triple-negative breast cancer. Ann. Oncol. (Suppl. 3) 30, III22 https://doi.org/10.1093/annonc/mdz095.069

Desantis C, Fedewa S, Goding Sauer A, Kramer J, Smith R, Jemal A (2015): Breast cancer statistics, 2015: Convergence of incidence rates between black and white women. CA Cancer J. Clin. 66, 31-42 https://doi.org/10.3322/caac. 21320

Donepudi MS, Kondapalli K, Amos SJ, Venkanteshan P (2014): Breast cancer statistics and markers. J. Cancer Res. Ther. 10, 506-511

Dreyer MS, Nattinger AB, Mcginley EL, Pezzin LE (2017): Socioeconomic status and breast cancer treatment. Breast Cancer Res. Treat. 167, 1-8 https://doi.org/10.1007/s10549-017-4490-3

Eduardo MR, Sergio VA (2012): Perspectives of long non-coding RNAs in cancer diagnostics. Front. Genet. 3, 32-44 https://doi.org/10.3389/fgene.2012.00032

Fan Zhang TX, Huizhen Chen, Shiquan Liu, Qingyi Yang (2001): The predictive value of P-pg and GST- $\pi$ expression for chemotherapy resistance in ovarian cancer. Chinese J. Oncol. 23, 313-316

Fojo T, Coley HM (2007): The role of efflux pumps in drug-resistant metastatic breast cancer: new insights and treatment strategies. Clin. Breast Cancer 7, 749-756
https://doi.org/10.3816/CBC.2007.n.035

Fu J, Dong GJ, Shi H, Zhang JF, Ning ZC, Bao XN, Liu CJ, Hu J, Liu MH, Xiong B (2019): LncRNA MIR503HG inhibits cell migration and invasion via miR-103/OLFM4 axis in triple negative breast cancer. J. Cell. Mol. Med. 23, 4738-4745

https://doi.org/10.1111/jcmm.14344

Gibb EA, Brown CJ, Wan LL (2011): The functional role of long non-coding RNA in human carcinomas. Mol. Cancer 10, 38 https://doi.org/10.1186/1476-4598-10-38

Gradishar WJ, Anderson BO, Balassanian R, Blair SL, Burstein HJ, Cyr A, Elias AD, Farrar WB, Forero A, Giordano SH (2017): NCCN guidelines insights: breast cancer, version 1, 2017. J. Natl. Compr. Canc. Netw. 15, 433-451

Guan YY, Bhandari A, Xia EJ, Yang F, Xiang JJ, Wang OC (2019): lncRNA FOXD3-AS1 is associated with clinical progression and regulates cell migration and invasion in breast cancer. Cell Biochem. Funct. 37, 239-244 https://doi.org/10.1002/cbf.3393

Hatok J, Racay P (2016): Bcl-2 family proteins master regulators of cell survival. Biomol. Concepts 7, 259-270 https://doi.org/10.1515/bmc-2016-0015

Hu X, Feng HF, Huang HX, Gu W, Fang QY, Xie Y, Qin C, Hu XW (2019): Downregulated long noncoding rna part1 inhibits proliferation and promotes apoptosis in bladder cancer. Technol. Cancer Res. Treat. 18, 1-9 https://doi.org/10.1177/1533033819846638

Ichim G, Tait SW (2016): A fate worse than death: apoptosis as an oncogenic process. Nat. Rev. Cancer 16, 539-548 https://doi.org/10.1038/nrc.2016.58

Kang M, Ren MP, Li Y, Fu YQ, Deng MM, Li CP (2018): Exosomemediated transfer of lncRNA PART1 induces gefitinib resistance in esophageal squamous cell carcinoma via functioning as a competing endogenous RNA. J. Exp. Clin. Cancer Res. 37,171

https://doi.org/10.1186/s13046-018-0845-9

Kong XL, Duan Y, Sang YT, Li YM, Zhang HW, Liang YR, Liu Y, Zhang N, Yang QF (2019): LncRNA-CDC6 promotes breast cancer progression and function as ceRNA to target CDC6 by sponging microRNA-215. J. Cell. Physiol. 234, 9105-9117 https://doi.org/10.1002/jcp.27587

Li J, Meng H, Bai Y, Wang K (2016): Regulation of lncRNA and its role in cancer metastasis. Oncol. Res. 23, 205-217 https://doi.org/10.3727/096504016X14549667334007

Mao Q (2005): Role of the breast cancer resistance protein (ABCG2) in drug transport. AAPS J. 7, E118-E133 https://doi.org/10.1208/aapsj070112

Masoud V, Pagès G (2017): Targeted therapies in breast cancer: New challenges to fight against resistance. World J. Clin. Oncol. 8, 120-134 https://doi.org/10.5306/wjco.v8.i2.120

Ming-Yu DU, Yin L, Xia HE, University XM, Hospital JC (2017): Research progress and clinical prospect of Lnc RNA in tumor invasion and metastasis. J. Chinese Oncol. 1, 54-59

Nie FQ, Sun M, Yang JS, Xie M, Xu TP, Xia R, Liu YW, Liu XH, Zhang EB, Lu KH, Shu YQ 2015): Long noncoding RNA ANRIL promotes non-small cell lung cancer cell proliferation and inhibits apoptosis by silencing KLF2 and P21 expression. Mol. Cancer Ther. 14, 268-277 
https://doi.org/10.1158/1535-7163.MCT-14-0492

Ong CC, Gierke S, Pitt C, Sagolla M, Cheng CK, Wei Z, Jubb AM, Strickland L, Schmidt M, Duron SG (2015): Small molecule inhibition of group I p21-activated kinases in breast cancer induces apoptosis and potentiates the activity of microtubule stabilizing agents. Breast Cancer Res. 17, 59 https://doi.org/10.1186/s13058-015-0564-5

Shi Y, Liu Y, Wang J, Jie D, Yun T, Li W, Yan L, Wang K, Feng J (2015): Downregulated long noncoding RNA BANCR promotes the proliferation of colorectal cancer cells via downregualtion of p21 expression. PloS One 10, e0122679 https://doi.org/10.1371/journal.pone.0122679

Shi Y, Yang F, Sun Z, Zhang W, Gu J, Guan X (2017): Differential microRNA expression is associated with androgen receptor expression in breast cancer. Mol. Med. Reports 15, 29-36 https://doi.org/10.3892/mmr.2016.6019

Siegel RL, Miller KD, Jemal A (2015): Cancer Statistics, 2017. CA Cancer J. Clin. 60, 277-300 https://doi.org/10.3322/caac.20073

Sun M, Geng DH, Li SQ, Chen ZF, Zhao WY (2018): LncRNA PART1 modulates toll-like receptor pathways to influence cell proliferation and apoptosis in prostate cancer cells. Biol. Chem. 399, 387-395 https://doi.org/10.1515/hsz-2017-0255

Sun T, Song Y, Yu H, Luo X (2019a): Identification of lncRNA TRPM2-AS/miR-140-3p/PYCR1 axis's proliferates and antiapoptotic effect on breast cancer using co-expression network analysis. Cancer Biol. Ther. 20, 760-773 https://doi.org/10.1080/15384047.2018.1564563
Sun XF, Huang T, Liu ZZ, Sun MM, Luo SX (2019b): LncRNA SNHG7 contributes to tumorigenesis and progression in breast cancer by interacting with miR-34a through EMT initiation and the Notch-1 pathway. Eur. J. Pharmacol. 856, 10 https://doi.org/10.1016/j.ejphar.2019.172407

Wu JJ, Chen H, Ye MN, Wang B, Zhang YZ, Sheng JY, Meng T, Chen HF (2019): Downregulation of long noncoding RNA HCP5 contributes to cisplatin resistance in human triple-negative breast cancer via regulation of PTEN expression. Biomed. Pharmacother. 115, 108869 https://doi.org/10.1016/j.biopha.2019.108869

Wang XL, Chen T, Zhang Y, Zhang N, Li C, Li YM, Liu Y, Zhang HW, Zhao WJ, Chen B, et al. (2019): Long noncoding RNA Linc00339 promotes triple-negative breast cancer progression through miR-377-3p/HOXC6 signaling pathway. J. Cell. Physiol. 234, 13303-13317 https://doi.org/10.1002/jcp.28007

Xie N (2009): Expression of cyclooxygenase 2 and cell cycle regulated protein - dependent kinase CDK2 in gastric cancer. Journal of University of South China 37, 703-704

Yang J, Meng XL, Yu Y, Pan L, Zheng QH, Lin W (2019): LncRNA POU3F3 promotes proliferation and inhibits apoptosis of cancer cells in triple-negative breast cancer by inactivating caspase 9. Biosci. Biotechnol. Biochem. 83, 1117-1123 https://doi.org/10.1080/09168451.2019.1588097

Received: September 5, 2019

Final version accepted: February 12, 2020

First published online: July 23, 2020 